\title{
3. THE ROLE OF ARTS IN SCHOOL EDUCATION
}

\section{Ana-Maria Aprotosoaie-Iftimi ${ }^{219}$}

\begin{abstract}
Contemporary psychologist Didier Anzieu ${ }^{220}$ speaks of five phases of the process of creation: creative emotion, gaining consciousness, transposition, elaboration, and exposure. Each of the five phases has a correspondent in the stages of development of visual-plastic educational activities, and the role of the teacher is essential in each of them. Starting from the five phases, we propose an approach pattern to the creative process, adapted and developed during the years of experience in pre-university educational environment, and refined throughout the research activity carried out in the university environment.
\end{abstract}

Key words: creative process, creative behavior, vizual art teacher, creative child

\section{Introduction}

Art is important because it is an essential component of human culture, heritage and creativity, summing up ways to know, present, represent, interpret and symbolize human experience. Contact with art with art requires the ability to ask, explore and compare, involving the expansion and development of one's own ideas and others' ideas. Artistic creation requires a certain professional specificity, an adaptation to work discipline and the ability to respond positively to challenges.

In 1999, the United Nations Educational, Scientific and Cultural Organization (UNESCO) launched an International Call for the Promotion of Artistic Education and Creativity in Schools as part of Culture Development for Peace. Violinist and conductor Yehudi Menuhin, present at the event together with other international artists, said that "there is a lack of mediation and creativity everywhere, especially in schools. Arts are missing from our lives, which makes way for violence." 221 The call argued that we need to become "clearly and strongly aware of the importance of the influence of creative spirit in the formation of human personality, fully developing the full potential of children and adolescents and maintaining the emotional balance, which are factors that foster harmonious behaviors".222

People of all historical times have sought and will seek answers to questions about their own existence. Each culture develops symbols through which the understanding, knowledge and vision obtained from this searchis are shared and

\footnotetext{
${ }^{219}$ Lecturer PhD., "George Enescu" National University of Arts from Iaşi, Romania, email: anamariaiftimi@gmail.com

${ }^{220}$ Anzieu Didier, Le corps de l'œuvre, Gallimard, Bibliothèque de l'inconscient, Paris, 1981, pag. 377.

${ }^{221}$ UNESCO Appeals for the Promotion of Arts Education and Creativity at School to help Construct a Culture of Pace, Paris, November 3 \{No.99-241\}

UNESCOPRESSE, http://www.://www.unesco.org/education/ecp/art_edu.htm, Paragraph 2.

222 Idem, Paragraph 3.
} 
passed on. The basics of communication are words, movements, touches, sounds, rhythm and images. In many cultures, the expression that communicates the perception of touching one's inner self and causes the opening of the human mind to reflection is called art. Throughout history, different ways of artistic expression received various labels. It is important to realize that, although terms like dance, music, drama, fine art are used all over the world, the deep meanings of these words differ from one culture to another. Thus, any list of the fields of art should only be seen from the perspective of a pragmatic characterisation, never exclusive and always evolving. A complete list cannot be presented here either, but an indicative attempt may include performing arts (dance, drama, music), literature and poetry, crafts, design, digital arts, visual arts, film, media, photography, and the list remains open. In order to be taught, learned, aquired, art can be introduced gradually, "through artistic experiences and practices, and their value must be maintained not only through the results of the process, but by the process in itself". ${ }^{223}$ Moreover, because many artistic forms cannot be limited to a single discipline, it is important to place particular emphasis on the interdisciplinary character of the arts and on the common aspects of variousfields and artistic forms and formulas.

\section{Cognition and emotion through artistic education}

Imagination, creativity and innovation are present in every person, even if sometimes only in a potential state; and therefore they can be cultivated and applied. Between these three basic processes there are close conections: imagination is the characteristic of human intelligence, creativity is the ability of the imagination to be properly applied, and innovation complements the process by using critical judgment in the development and application of an idea. In this study we assume that all people have a creative potential. Arts provide the environment and determine the practice of creative development, thus cultivating imagination, emotional intelligence, individual and collective initiative, critical thinking and free action ${ }^{224}$.

At the same time, artistic education stimulates cognitive development in relevant directions so that beneficiaries are adapted to the needs of the society in which they live. Experimentation and development of knowledge and appreciation of art allow "the development of unique perspectives in a wide range of areas, perspectives that cannot be discovered by other means of education". 225 In order for adults and children to actively participate in cultural and artistic life, they need to progressively learn, understand, appreciate and experience diverse artistic expressions, share and explore various aspects of life.

According to researchers Mary Helen, Immordino-Yang and Antonio

\footnotetext{
${ }^{223}$ Unesco, Road Map for Arts Education The World Conference on Arts Education: Building Creative Capacities for the 21st Century, Lisbon, 6-9 March 2006, p. 7, http://www.unesco.org/new/fileadmin/MULTIMEDIA/HQ/CLT/CLT/pdf/Arts_Edu_RoadMap_en.pdf , ${ }^{224}$ Idem., 4, p. 4.

${ }^{225}$ Idem., p. 5.
} 
Damasiao $^{226}$ nowadays one can notice the growing differences between cognitive and emotional processes, differences caused by the increased emphasis on learning environments, on developing cognitive sabilities, while emotional processes are less valuable. This emphasis on cognitive capacities at the expense of the emotional sphere is an important factor in the tendencies of moral decline of contemporary society. Cognitive capacities, but equally, emotional capacities are becoming more and more important in order to meet the challenges of the present century. Due to social changes affecting family structures, children are often deprived of parental attention. Due to the lack of communication and close relationships in family life, children are exposed to problems they are unable to cope with emotionally. Moreover, the transmission of cultural values and artistic practices in the family environment is becoming more cumbersome in rural areas, and in urban areas it is almost entirely lost.

In decision-making, emotional processing is an active part for various actions and ideas, setting the direction of reflection and judgment. Without emotional involvement, any decision, action or idea will be based solely on purely rational terms. The consciousness of moral behavior, which is part of the solid preparation of being a citizen, requires emotional participation. 21st century societies are increasingly demanding creative, flexible, adaptable and innovative individuals, so education systems need to evolve in such a way as to provide conditions for both cognitively and emotionally balanced development. Artistic education is able to develop these skills, encouraging free expression, critical environmental evaluation, and active engagement in various aspects of human existence.

Therefore, this factor can also be seen as a means of developing the human resources needed for a valuable cultural capital. Human resources and cultural capital are the key to developing powerful and sustainable cultural institutions (museums, cultural centers, galleries, theatres, musical events) and cultural industries (music, film, television, advertising, media), which are ways to access culture and arts and which are a good indicator and facilitator for the economic growth of society. As a result, education programmes through and for art can facilitate the discovery of a variety of cultural expressions offered by cultural institutions and industries, but, at the same time, they also develop the ability to critically respond to cultural productions. In contrast, these cultural entities serve as a resource for educators to incorporate art into education.

\section{Education for art, through art, with the help of art}

In all cultures, art is an integral part of life, an area that provides an optimal framework in which creation and learning are interconnected. The benefit of introducing arts and cultural practices in learning environments results in an

\footnotetext{
${ }^{226}$ Immordino - Ian- Yang, Mary Helen, Damasio Antonio R., We Feel Therefore, We Learn: The Relevance of Affective and Social Neuroscience to Education, Article Published In Mind, Brain and Education Volume 1, Issue 1, pages 3-10, March 2007, pp. 3-10.
} 
intellectual, emotional and psychological balance in the development of individuals and society. A study published in 2006, applied to forty states and international organisations, led by UNESCO in collaboration with the International Federation of Arts Councils and Culture Agencies (IFACCA) and the Australia Council for the Arts (OZCO), ${ }^{227}$ highlights that: a) arts are included in educational policies all over the world; arts are differentiated according to specific cultural contexts, and the biggest differences arise between economically developed and developing states; b) arts serve different purposes, including education for art and education through art. UNESCO supports two main approaches to artistic education, which can be implemented simultaneously but which, at the same time, must remain distinct. Art can be addressed in education as a study of individual disciplines and will therefore develop both sensitivities, processes, knowledge, specific artistic skills, and the ability to appreciate art.

Education that emphasizes the value of various cultural - artistic, multi- and inter-cultural perspectives, of specific artistic languages, is education for art. Instead, education through art or "arts in education" (IEA) 228 is seen as a cumulation of learning and teaching methods in which skills, knowledge and processes are engaged throughout the curriculum for very varied purposes, and cultural and artistic dimensions are included in all subjects in the curriculum. The approach to learning through art/culture underlines how traditional and contemporary cultural expressions, resources and practices can be used as learning tools. Specifically, the second approach highlights the potential of art to play an instrumental role, both formally and conceptually, as a vehicle to convey knowledge and mobilize learning methods for different disciplines.

Arts and cultural traditions related to them are a means of addressing and/or understanding much more deeply the general subjects or disciplines of the curuiculum. For example, the use of colors and shapes in mural painting and architecture, to teach subjects from various exact or humanities disciplines, but also in teaching other forms of art. By embracing the "Multiple Intelligences" 229 theory, proposed by psychologist Howard Gardner in 1980, art education approach aims to expand the benefits of artistic education for all beneficiaries of education and for all disciplines. At the same time, it is aimed to contextualize this approach through practical applications of artistic disciplines. In order to be effective, this interdisciplinary approach requires changes in both teacher training and in the methods used. The instrumental approach of art does not limit art to an additional educational tool, but it causes an integrative approach, without neglecting its existence in the curriculum as a main or stand-alone subject of

\footnotetext{
227 Bamford Anne The WOW factor: Global research compedium on the impact of the arts in education, Munster Publishing House, Germany: Waxmann Verlag GmbH, 2006, p. 104.

228 UnescoRoad Map for Arts Education The World Conference on Arts Education: Building Creative Capacities for the 21st Century, Lisbon, 6-9 March 2006, p. 8, http://www.unesco.org/new/fileadmin/MULTIMEDIA/HQ/CLT/CLT/pdf/Arts_Edu_RoadMap_en.pdf.

229 Gardner Howard, Multiple intelligences. New horizons for theory and practice, Sigma Publishing House, Bucharest, 2007.
} 
study. The third generally accepted approach involves the intersecting of arts and other curricular disciplines, a way that guarantees learning with the help of the arts. In this orientation, arts are engaged for a variety of social purposes, such as identifying people with special needs or assimilating notions of health and wellbeing. ${ }^{230}$

In recent years, education has a tendency to narrow its focus area by focusing on those academic skills that can be tested and hold a large stake in evaluation, while other aspects of the development of the individual are ignored. Opposite this general trend, an alternative direction is "holistic education", which balances and envisages the cultivation and development of all dimensions of the individual, including both physical/sensory, emotional/cognitive aspects, as well as social, moral and spiritual ${ }^{231}$ attributes. The holistic approach is relatively new in the field of artistic education, but recognition of its importance is highlighted by recent publications on this topic.

\section{Conclusions}

All these approaches in the fields of arts and education have prompted strong debates, in the sense "that they represent the applied benefits of artistic education rather than the cultural or intrinsic values of the arts itself". ${ }^{232}$ The aspect that is increasingly highlighted in contemporaryity is the fact that arts play a multitude of roles in understanding what it means to live in communities, whether they are from the same street, from the same neighborhood or anywhere in the world, meaning that "the world perceived from one place is not the entire world". ${ }^{233}$

The present historical period is determined by global economic development, neo-liberalism (targeting economic control from the public to private sector), religious tensions, etc. As far as education is concerned, we notice the development of the theory of critical pedagogy/education, which promotes the ideology of education as an instrument of social development in order to achieve social, cultural and economic fairness. It emphasizes the feature of objects, phenomena and human behavior of being dispensable, easy to replace, lacking durability. Short-term or even single-term handy. These aspects are found globally and are increasingly important even at a national level due to the development of the current "consumer society".

In this complex setting, visual artistic education has the potential to play an

\footnotetext{
${ }^{230}$ Mills \& Brown, 2004, apud, Wright PEther, Teaching in Arts Education Article Published In Saha Lawrence J. \& Dworkin Gary (Ed.), International Handbook of Research on Teachers and Teaching. Publishing Springer International Handbooks of Education, Volume 21, 2009, pp 1029 - 1040.

231 Campbel Laurel H, Holistic Art Education: A transformative Approach to Teaching Art article published in the journal Art Education, March 2011; 64, 2; Arts \& Humanities, pp. 18-22.

${ }_{232}$ McCarthy, Ondaatje, Zakaras, \& Brooks, 2004, apud. Wright PEther, Teaching in Arts Education Article Published In Saha Lawrence J. \& Dworkin Gary (Ed.), International Handbook of Research on Teachers and Teaching. Publishing Springer International Handbooks of Education, Volume 21, 2009 p. 1030.

233 Greene Maxine, Releasing the imagination: Essays on education, the arts, and social change, Jossey-Bass Publishing House, San Francisco, 1995, p. 5.
} 
important role in educating young people around the world. This role involves contributing to the development of critical thinking, creativity and personal, cultural and social awareness of young people, a role that indicates the social importance of artistic education.

\section{References}

1. Bamford, A., (2006), The WOW factor: Global research compedium on the impact of the arts in education, Munster Publishing House, Germany: Waxmann Verlag $\mathrm{GmbH}$.

2. Gardner, H., (2007), Multiple intelligences. New horizons for theory and practice, Sigma Publishing House, Bucharest.

3. Greene, M., (1995), Releasing the imagination: Essays on education, the arts, and social change, Jossey-Bass Publishing House, San Francisco.

4. Immordino - Ian- Yang, Mary Helen, Damasio Antonio R., We Feel Therefore, We Learn: The Relevance of Affective and Social Neuroscience to Education, Article Published In Mind, Brain and Education Volume 1, Issue 1, pages 3-10, March 2007, pAg. 3-10.

5. Mills \& Brown, (2004), apud, Wright PEther,Teaching in Arts Education Article Published In Saha Lawrence J. \& Dworkin Gary (Ed.), International Handbook of Research on Teachers and Teaching. Publishing Springer International Handbooks of Education, Volume 21, 2009, pp 1029 - 1040.

6. Campbel L., H., (2011), Holistic Art Education: A transformative Approach to Teaching Art article published in the journal Art Education, March 2011; 64, 2; Arts \& Humanities, pp. 18-22.

7. McCarthy, Ondaatje, Zakaras, \& Brooks, (2004), apud. Wright PEther, Teaching in Arts Education Article Published In Saha Lawrence J. \& Dworkin Gary (Ed.), International Handbook of Research on Teachers and Teaching. Publishing Springer International Handbooks of Education, Volume 21, 2009.

8. UNESCO, (2006), Appeals for the Promotion of Arts Education and Creativity at School to help Construct a Culture of Pace, Paris, November 3 \{No.99-241\}

UNESCOPRESSE,http://www.://www.unesco.org/education/ecp/art_edu.htm, 19.09.2019, 20:20.

9. Unesco, (2006), Road Map for Arts Education The World Conference on Arts Education: Building Creative Capacities for the 21 st Century, Lisbon, 6-9 March 2006,http://www.unesco.org/new/fileadmin/MULTIMEDIA/HQ/CLT/CLT/pdf/ Arts_Edu_RoadMap_en.pdf , 13.08.2019, 09:30. 